IRA-International Journal of Technology \& Engineering ISSN 2455-4480; Vol.07, Issue 01 (2017)

Pg. no. 1-9

Institute of Research Advances

http://research-advances.org/index.php/IRAJTE

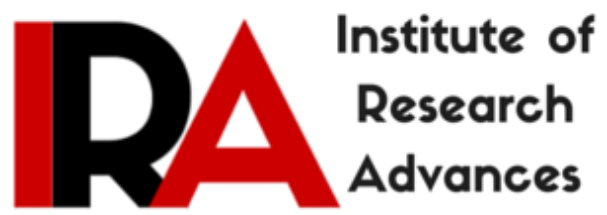

\title{
Gesture Control of Robotic Arm
}

\author{
Dharshan Y. ${ }^{1}$, Vivek S. ${ }^{2}$, Saranya S. ${ }^{3}$, Aarthi V.R. ${ }^{4}$, Madhumathi T. \\ ${ }^{1,2}$ Assistant Professor, Department of EIE \\ Sri Ramakrishna Engineering College, Coimbatore, India. \\ ${ }^{3,4,5}$ Student, Department of EIE \\ Sri Ramakrishna Engineering College, Coimbatore, India.
}

Type of Reviewed: Peer Reviewed.

DOI: http://dx.doi.org/10.21013/jte.v7.n1.p1

\begin{abstract}
How to cite this paper:
Y., Dharshan, S., Vivek, S., Saranya, V.R., Aarthi, \& T., Madhumathi (2017). Gesture Control of Robotic Arm. IRA-International Journal of Technology \& Engineering (ISSN 2455-4480), 7(1),
\end{abstract} 1-9. doi:http://dx.doi.org/10.21013/jte.v7.n1.p1

(C) Institute of Research Advances

(cc) EY-NG

This work is licensed under a Creative Commons Attribution-Non Commercial 4.0 International License subject to proper citation to the publication source of the work.

Disclaimer: The scholarly papers as reviewed and published by the Institute of Research Advances (IRA) are the views and opinions of their respective authors and are not the views or opinions of the IRA. The IRA disclaims of any harm or loss caused due to the published content to any party. 


\section{ABSTRACT}

Robots have become a key technology in various fields. Robotic arms are mostly remote controlled by buttons or panels and sometimes in batch process they are autonomous. The usage of panel boards or control sticks includes a lot of hardwiring and subject to malfunction. It also induces some stress on the operators. Hence major chemical industries like cosmetic manufacturing, paint manufacturing and Biosynthesis laboratory etc., which deals with hazardous environment due to the chemicals and other bio substances, involve humans for the processing. The aim is to reduce the bulk of wiring in the robotic arms and reduce the effort and number of operators in controlling the robotic arm operations. To implement gestures into the process this would be a major breakthrough. This can also be used as pick \& place robot, a cleaning robot in chemical industries where a human does not need to directly involved in the process of cleaning the chemicals and also for coating underground tanks.

Keywords—robotic arm, gestures, hazardous environment.

\section{INTRODUCTION}

Robotics is the branch of mechanical engineering, electrical engineering and software engineering that deals with the design, construction, operation, application, control systems and information processing of robots.

These technologies are used as automated machines that can take the place of humans in dangerous environments or manufacturing processes. Many of today's robots are inspired to the field of bioinspired robotics.

The concept of creating machines that can operate autonomously dates back to classical times, but research into the functionality and potential uses of robots did not grow substantially until the 20th century. Robotics has been often seen to mimic, and often manage tasks in a human behaviour. Robots also do jobs that are hazardous to people such as defusing bombs, underground paintings, mines and exploring shipwrecks.

\section{GENERAL DISCUSSION}

\section{A. Methodogy}

The proposed methodology have implemented a system through which user can give the commands to the robotic arm with the help of a camera which captures the objects gesture movement [1] [4].The robotic arm can be used where a human feel he or she may not directly involve with substance or hazardous materials in the industries.

\section{B. Block Diagram}

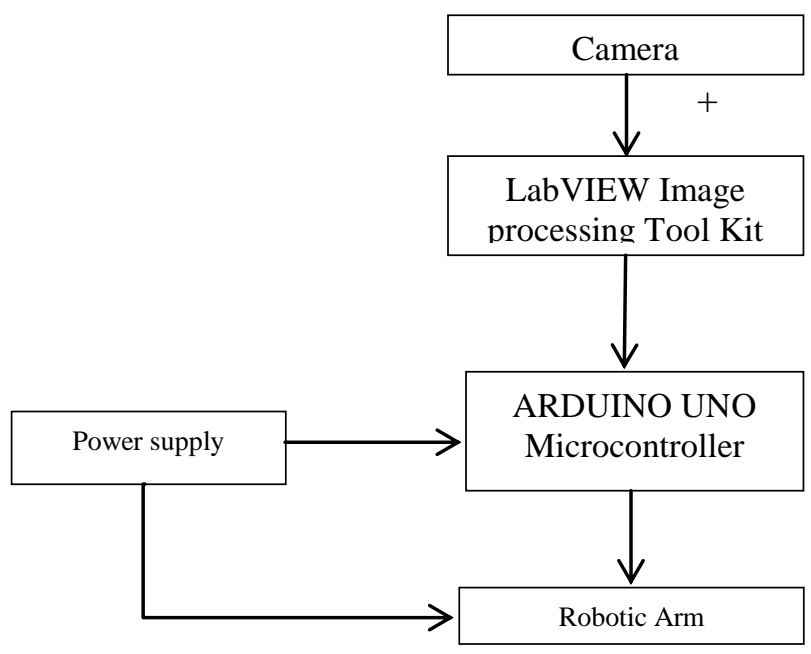

Fig.1. Block diagram for the proposed system 


\section{Expected benefits to the target groups}

1) An alternative for the scarce human labour for heavy lifting.

2) Eliminate the usage of human error in handling of toxic and fragile objects.

3) Prevent back pain/back injuries due to constant bending over by the Operator.

4) Increase productivity and efficiency.

\section{Existing Method}

The project "Wireless Gesture Controlled Robotic Arm with Vision" is a system design which is divided into Accelerometer, Robotic Arm and Platform. It is an Accelerometer based system which controls a Robotic Arm wirelessly using a3-axis (DOF's) accelerometer via RF signals. The Robotic Arm is mounted over a movable platform that is controlled wirelessly by another accelerometer. One accelerometer is attached on the human hand, capturing its gestures and postures according to which the robotic arm moves and the other accelerometer is mounted on any one of the leg of the operator, capturing its gestures and postures and thus the platform moves accordingly. Overall, the robotic arm and platform is synchronized with the gestures and postures of the hand and leg of the operator, respectively. The robotic arm performs the following motions: PICK and PLACE, RAISING and LOWERING the objects. FORWARD, BACKWARD, RIGHT and LEFT are the motions performed by the platform. The system is equipped with an IP based camera that can stream real time video wirelessly to any Internet enabled device such as Mobile Phone, Laptop, etc.

\section{IV.PROPOSED METHOD}

\section{Components specification}

\section{SOFTWARE USED}

- LabVIEW 2014

- Vision and Motion Toolkit

\section{HARDWARES USED}

\section{CAMERA}

- PC web camera.

-1600X1200 pixel resolution

\section{SERVO MOTORS}

- $10 \mathrm{~kg}$ torque

- Metal geared

- Motor weight 50g

- Operating voltage 5V

ARDUINO UNO

- 14 digital input/output pins

- 6 analog inputs

- $16 \mathrm{MHz}$ ceramic resonator

- Operating Voltage 5V

- Input Voltage 7-12V

- Flash memory 32KB 


\section{E. Kinematic Modelling of the Robot}

\section{FORCE CALCULATIONS OF JOINTS}

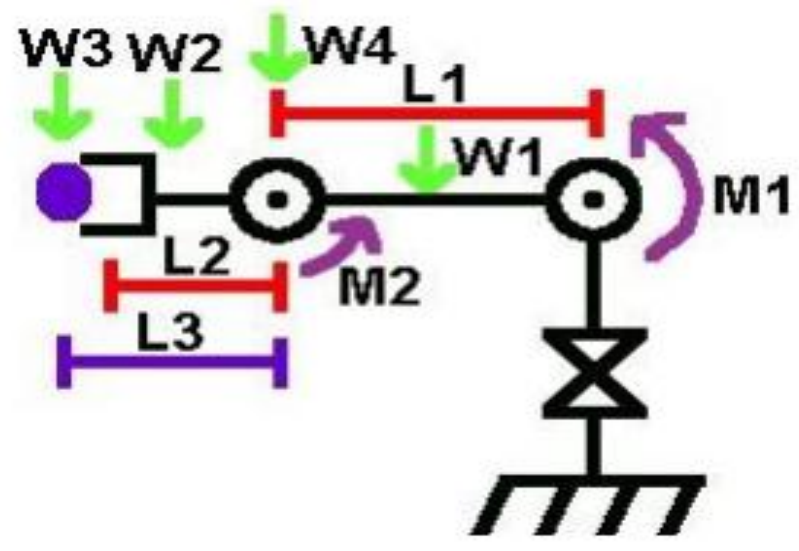

Fig.2.Force calculation

The force calculations are done for motor selection. You must make sure that the motor you choose should not only support the weight of the robot arm, but also what the robot arm will carry (the blue ball in the fig below).

The first step is to label the FBD, with the robot arm stretched out to its maximum length.

Next the moment arm calculation is done by multiplying downward force times the linkage lengths. The calculation must be done for each lifting actuator. This design has just two DOF[6] [11] that requires lifting, and the center of mass of each linkage is assumed to be Length/2.

Torque about Joint 1 :

$\mathrm{M} 1=\mathrm{L} 1 / 2 * \mathrm{~W} 1+\mathrm{L} 1 * \mathrm{~W} 4+(\mathrm{L} 1+\mathrm{L} 2 / 2) * \mathrm{~W} 2+(\mathrm{L} 1+\mathrm{L} 3) * \mathrm{~W} 3$

Torque About Joint 2:

$\mathrm{M} 2=\mathrm{L} 2 / 2 * \mathrm{~W} 2+\mathrm{L} 3 * \mathrm{~W} 3$

For each added DOF, the math gets more complicated, and the joint weights get heavier. It is also seen that shorter arm lengths allow for smaller torque requirements.

\section{FORWARD KINEMATICS}

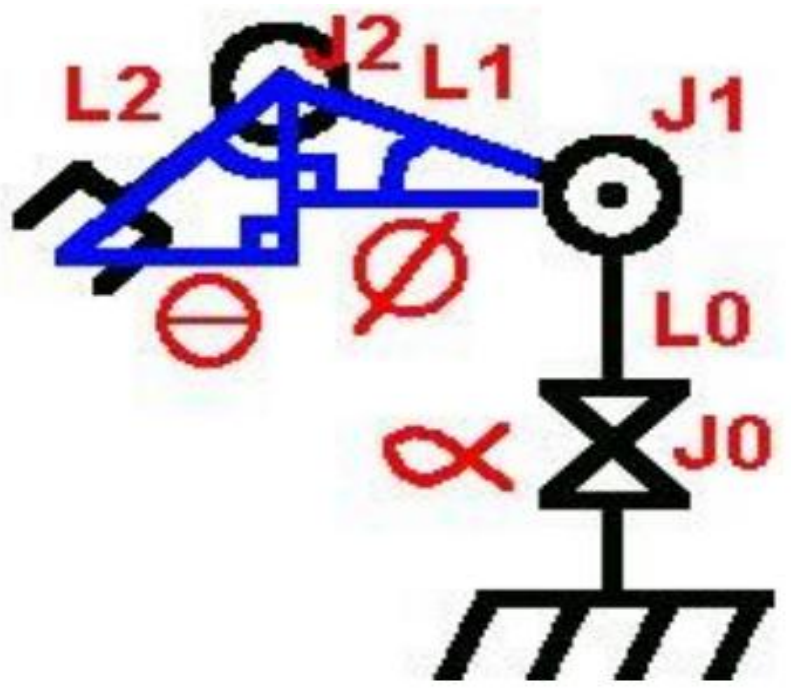

Fig.3. Forward kinematics 
Forward kinematics is the method for determining the orientation and position of the end effector, using the joint angles and link lengths of the robot arm.

Here the end effector location with given joint angles and link lengths is calculated. To make visualization easier, the blue triangles are drawn and the angles are labelled.

Assume that the base is located at $\mathrm{x}=0$ and $\mathrm{y}=0$. The first step would be to locate $\mathrm{x}$ and $\mathrm{y}$ of each joint.

Joint 0 (with $\mathrm{x}$ and $\mathrm{y}$ at base equaling 0 ):

$\mathrm{x} 0=0$

$\mathrm{y} 0=\mathrm{L} 0$

Joint 1 (with $\mathrm{x}$ and $\mathrm{y}$ at $\mathrm{J} 1$ equaling 0 ):

$\cos (\mathrm{psi})=\mathrm{x} 1 / \mathrm{L} 1 \Rightarrow \mathrm{x} 1=\mathrm{L} 1 * \cos (\mathrm{psi})$

$\sin (\mathrm{psi})=\mathrm{y} 1 / \mathrm{L} 1 \Rightarrow \mathrm{y} 1=\mathrm{L} 1 * \sin (\mathrm{psi})$

Joint 2 (with $\mathrm{x}$ and $\mathrm{y}$ at $\mathrm{J} 2$ equaling 0 ):

$\sin ($ theta $)=x 2 / \mathrm{L} 2 \Rightarrow \times \mathrm{x} 2=\mathrm{L} 2 * \sin ($ theta $)$

$\cos ($ theta $)=y 2 / L 2=y 2=L 2 * \cos ($ theta $)$

End Effector Location (make sure your signs are correct):

$\mathrm{x} 0+\mathrm{x} 1+\mathrm{x} 2$, or $0+\mathrm{L} 1 * \cos (\mathrm{psi})+\mathrm{L} 2 * \sin$ (theta)

$\mathrm{y} 0+\mathrm{y} 1+\mathrm{y} 2$, or $\mathrm{L} 0+\mathrm{L} 1 * \sin (\mathrm{psi})+\mathrm{L} 2 * \cos ($ theta $)$

$\mathrm{z}$ equals alpha, in cylindrical coordinates

The angle of the end effector, in this example, is equal to theta + psi.

INVERSE KINEMATICS

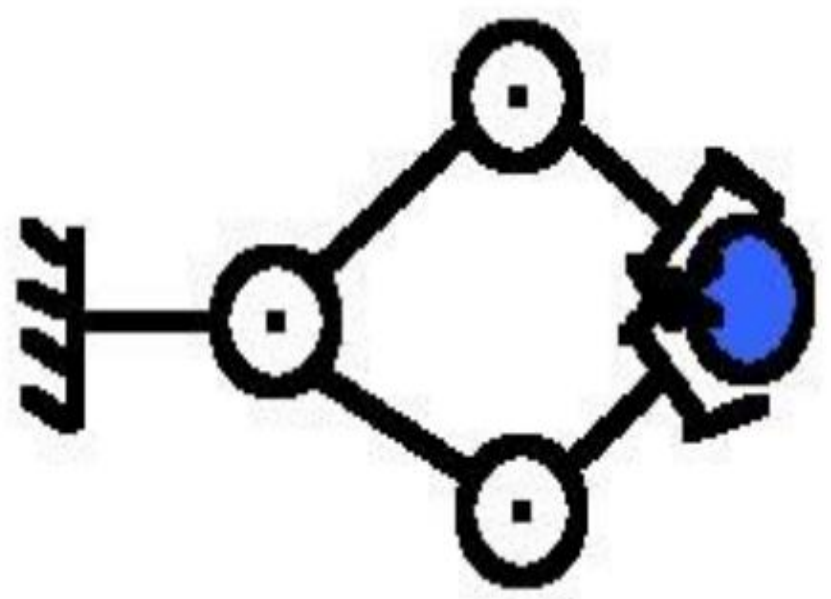

Fig.4. Inverse kinematics

Inverse kinematics is the opposite of forward kinematics. Here there is a desired end effector position, but need to know the joint angles required to achieve it. Inverse kinematics is more useful than forward kinematics, but the calculation is much more complicated.

$\mathrm{psi}=\arccos \left(\left(\mathrm{x}^{\wedge} 2+\mathrm{y}^{\wedge} 2-\mathrm{L} 1^{\wedge} 2-\mathrm{L} 2^{\wedge} 2\right) /(2 * \mathrm{~L} 1 * \mathrm{~L} 2)\right)$

theta $=\arcsin \left((\mathrm{y} *(\mathrm{~L} 1+\mathrm{L} 2 * \mathrm{c} 2)-\mathrm{x} * \mathrm{~L} 2 * \mathrm{~s} 2) /\left(\mathrm{x}^{\wedge} 2+\mathrm{y}^{\wedge} 2\right)\right)$

where

$\mathrm{c} 2=\left(\mathrm{x}^{\wedge} 2+\mathrm{y}^{\wedge} 2-\mathrm{L} 1 \wedge 2-\mathrm{L} 2 \wedge 2\right) /(2 * \mathrm{~L} 1 * \mathrm{~L} 2)$

ands $2=\operatorname{sqrt}(1-\mathrm{c} 2 \wedge 2)$. 


\section{F. Design And Implementation}

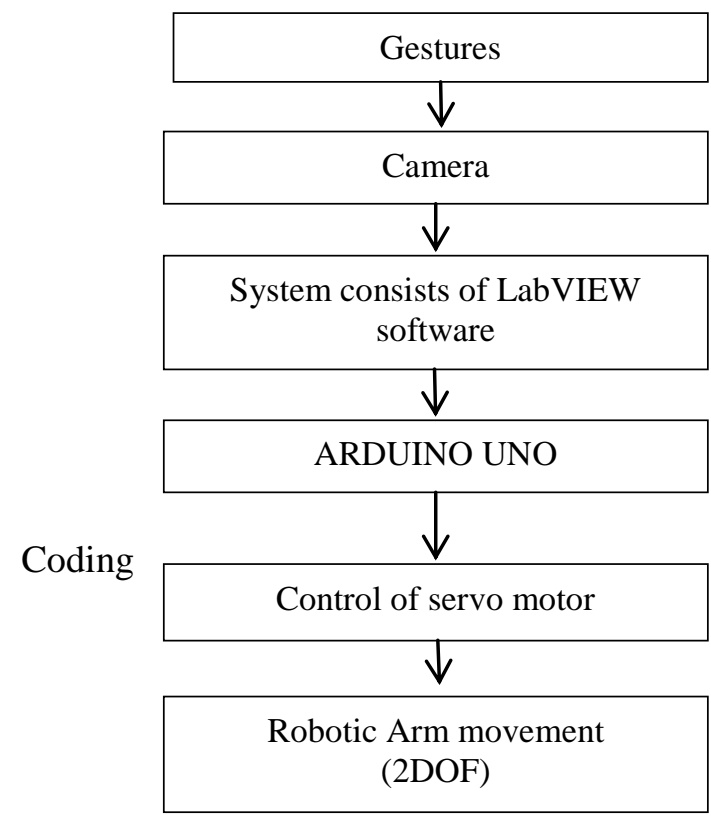

- The gesture movement of the object is captured using the camera [1] [4].

- The captured image is then processed using image processing technique through NI LabVIEW software[8].

- The ARDUINO UNO Microcontroller act as an interface between the system and the servo motors of the robotic arm.

- The power supply is given to the ARDUINO UNO Microcontroller and the servo motors.

- The robotic arm moves with the help of a servo motor where the movement is controlled by the PWM technique through the ARDUINO UNO Microcontroller[3][15].

- The robotic arm is introduced to the environment for its various applications[7] [13].

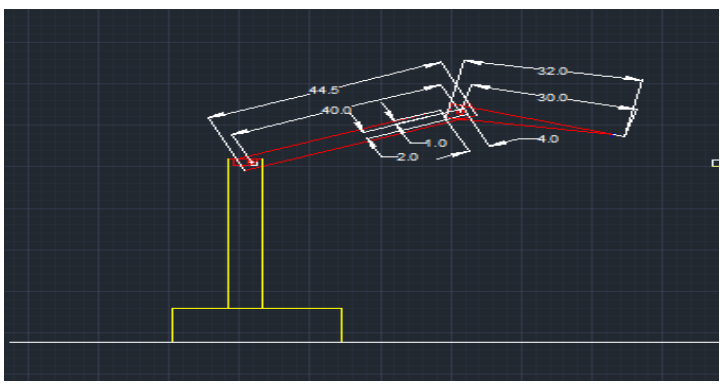

(a)

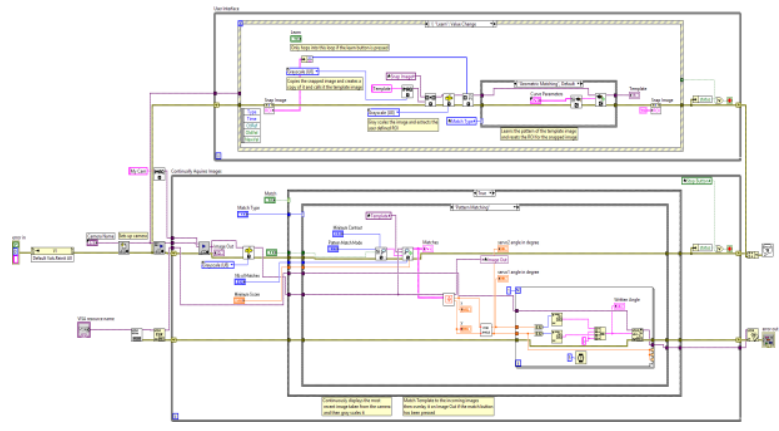

(b)

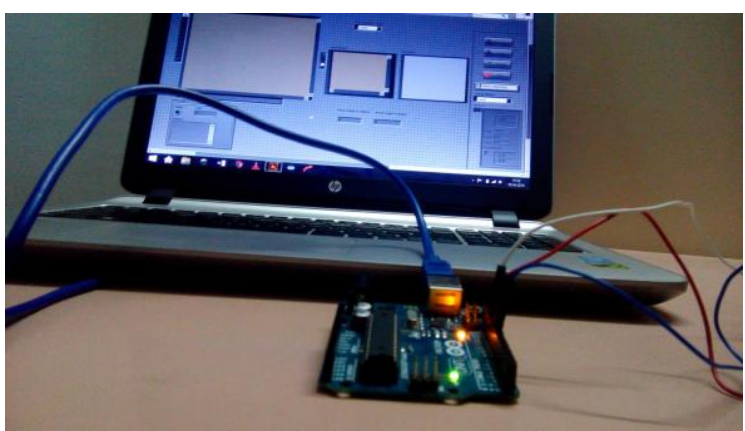

(c) 
Fig. 5. (a) Hardware construction prototype. (b) Block Diagram Code for the Robotic Arm. (c) LabVIEW Interface With Arduino.

\section{SOFTWARE USED}

The software used is LabVIEW (Laboratory Virtual Instrument Engineering Workbench). It is a system-design platform and development environment for a visual programming language from National Instruments.

The graphical language is named "G". It was released for the Apple Macintosh in 1986, LabVIEW is normallyused for data acquisition, instrument control, and industrial automation on a variety of platforms including Microsoft Windows, UNIX, Linux. The latest version of LabVIEW is LabVIEW 2016, released in August 2016.

\section{RESULTS}

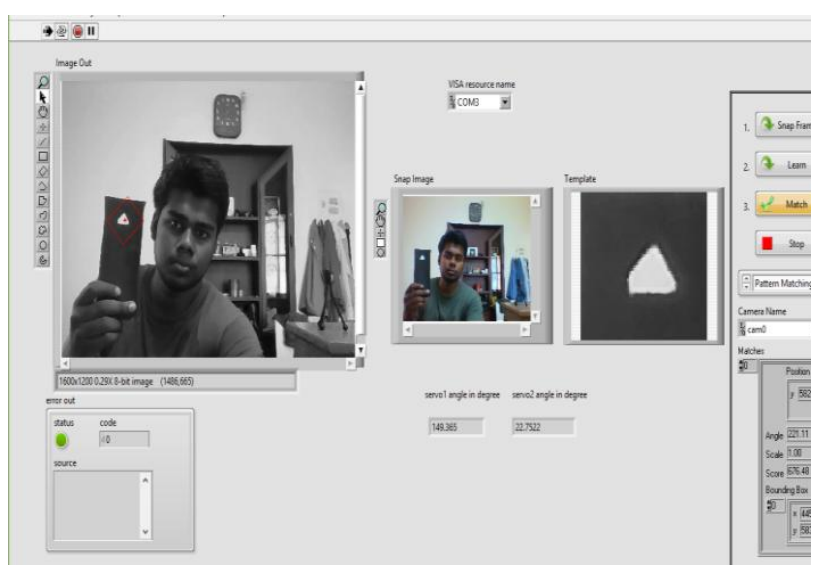

(a)

Fig. 6. (a) Front Panel Code of the Gesture Control.

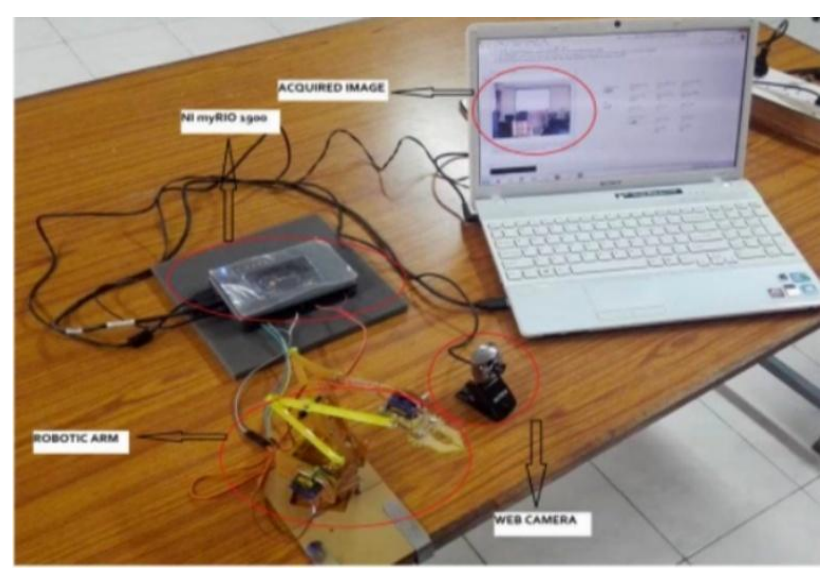

(b)

(b) Overall prototype.

\section{CONCLUSION}

A two degree of freedom robotic arm was designed using CAD from a sheet of 10mm PVC sheet. The robotic arm was controlled successfully using image processing by LabVIEW and driving the servos using ARDUINO UNO Microcontroller [15]. The robotic arm replicated or moved in accordance with the movement of the gesture or reference image[3]. By controlling the robotic arm through the gesture a pick and place of an object was performed[7] [13]. This method of robotic arm control can be used for handling heavy load. A heavy lifting crane can be controlled by gesture. In laboratories where toxic stuff are being handled an arm controlled by gestures will give a better interface of the users. As a future work the $2 \mathrm{D}$ processing can be upgraded to a 3D control using the gesture which would help lot of different purposes in different areas of the industries.

\section{ACKNOWLEDGMENT}

The authors would like to sincerely thank the Management, Director, Principal and the Head of the Department of Sri Ramakrishna Engineering College, Coimbatore for their constant support and providing us with the required facility.

\section{REFERENCES}

1. Asanterabi Malima, ErolOzgur, and Mujdat Cetin, 2006, “A Fast Algorithm for Vision-Based Hand Gesture Recognition for Robot Control", IEEE International Conference on Computer Vision.Vol.21, pp 10-55. 
2. Bertram, T., Bekes, F., Greul, R., Hanke, O., Hab, J., Hilgert, J., Miller, M., Ottgen, O., OpgenRhein, P., Torlo, M. and Ward, D. (2003) 'Modelling and simulation for Robotic design in automotion systems', Control Engineering Practice, Vol. 11, pp. 179-190.

3. Bhuyan,A.I. and Mallick,T.C.,(2014) "Gyro-accelerometer based control of a robotic Arm using AVR microcontroller" 9th International Forum Transactions(Tim)| Instrumentation \&Measurement Society,Vol.2 pp. $409-413$.

4. Chao Hy Xiang Wang, Mrinal K. Mandal, Max Meng, and Donglin Li , 2003, "Efficient Face and Gesture Recognition Techniques for Robot Control", Electronics and Instrumentation Engineering Research \&Publications, Vol. 3, pp. 1757-1762.

5. Jagdish Lal Raheja, RadheyShyam, Umesh Kumar and P Bhanu Prasad,2010, "Real-Time Robotic Hand Control using Hand Gestures", Second International Conference on Machine Learning and Computing,Vol. 21,pp. 12-62.

6. Le BanhDuc,Syaifuddin.M,TruongTrongToai ,Ngo HuyTan,Saad, M.N (2007) ”Designing 4 Degrees of Freedom Humanoid Robotic Arm", Lee ChanWai Intelligent and Advanced Systems,International Conference on Intelligent and Automation Systems International Conference,Vol.2,pp.1069-1074

7. Patel.H.K, Verma.P, Ranka.S (2011),"Design and development of co-ordinate based autonomous robotic arm Engineering", Nirma University IEEE CONFERENCE PUBLICATIONS, Vol.21 pp.1-6

8. Shaikh.A, Khaladkar.G, Jage.R, Taili T.P.J (2013),"Robotic Arm Movements Wirelessly Synchronized with Human Arm Movements Using Real Time Image Processing", India Educators' Conference Texas Instruments India educators' Conference,Vol.64, pp.277 - 284

9. Thomas G. Zimmerman, Jaron Lanier, Chuck Blanchard, Steve Bryson and Young Harvill, 1987, “A Hand Gesture Interface Device”,Conference Texas Instruments India educators' Conference, Vol. 15,pp.189-192.

10. 10.Wong GunaHalo,Y., Leck Lim Chot,R., (2011) "6-DOF PC-Based Robotic Arm (PCROBOARM) with efficient trajectory planning and speed control", 4 th International Conference IEEE Conference Publications Vol. 1,pp.1 - 7.

11. A. Elfasakhany, E. Yanez, K. Baylon and R. Salgado,(2011) "Design and Development of a Competitive Low-Cost Robot Arm with Four Degrees of Freedom," Modern Mechanical Engineering, Vol. 1 No. 2, 2011, pp. 47-55.

12. Fan Zhang, Yunping Zhu, Tomonari Furukawa, and WanqingSong,(2016) "Kinematic Analysis of a Partially Decoupled 3-DOF Parallel Wrist",Volume 2015 (2015), Article ID 790414, 9 pages.

13. B.O. Omijeh, R. Uhunmwangho, and M. Ehikhamenle,(2014) "Design Analysis of a Remote Controlled Pick and Place Robotic Vehicle", International Journal of Engineering Research and Development, Volume 10, PP.57-68. 
14. PanagiotaTsarouchi, Athanasios Athanasatos, Sotiris Makris, XenofonChatzigeoriou, and George Chryssolouris,(2016) "High Level Robot Programming Using Body And Hand Gestures", $5^{\text {th }}$ CIRP Global Web Conference - Research And Innovation For Future Production, Volume 55, pp.1-5.

15. Premangshu Chanda, PallabKanti Mukherjee, SubrataModak, AsokeNath,(2016) " Gesture Controlled Robot using Arduino and Android", International Journal of Advanced Research in Computer Science and Software Engineering, Volume 6, Issue 6. 